\title{
Sistemas de Produção de Grãos e Incidência de Plantas DANINHAS ${ }^{1}$
}

\author{
Weed Incidence in Grain Production Systems
}

CASTRO, G.S.A. ${ }^{2}$, CRUSCIOL, C.A.C. ${ }^{3}$, NEGRISOLI, E. ${ }^{4}$ e PERIM, L. ${ }^{5}$

\begin{abstract}
RESUMO - O sistema de semeadura direta e os diferentes sistemas de produção nele adotados podem contribuir para a supressão de plantas infestantes. Em razão disso, o objetivo do presente trabalho foi avaliar o controle de plantas daninhas em função de diferentes sistemas de produção de grãos. Os tratamentos utilizados foram: I. Sistema "safra-pousio" - soja/ pousio/milho/pousio/arroz/pousio/soja; II. Sistema "safra-adubo verde" - soja/milheto/ milho/guandu/arroz/crotalária/soja; III. Sistema "safra-safrinha" - soja/aveia-branca/milho/ feijão-da-seca/arroz/mamona/soja; IV. Sistema "safra - forrageira"- soja + braquiária/milho + braquiária/arroz + braquiária/soja. Em novembro de 2009 (após três safras agrícolas), foi realizado o levantamento de plantas daninhas infestantes. Para isso, foi utilizado um quadro $(0,3 \times 0,3 \mathrm{~m})$, lançado aleatoriamente quatro vezes dentro de cada parcela. As plantas foram identificadas, bem como feita a determinação do número total das espécies invasoras, da massa seca e da porcentagem de controle das espécies de acordo com o sistema de produção. Foi realizada ainda a análise fitossociológica da comunidade de plantas daninhas infestantes. Os sistemas safra-adubo verde, safra-safrinha e safra-forrageira apresentaram bom controle de plantas infestantes quando comparados ao sistema safra-pousio. Portanto, a presença de algum tipo de cobertura é importante para manter as características do solo favorável e um bom controle de plantas invasoras.
\end{abstract}

Palavras-chave: rotação de cultura, planta daninha, adubo verde, safrinha, integração lavoura-pecuária.

\begin{abstract}
Tillage and other agricultural production systems can contribute to weed suppression. Thus, the objective of this study was to evaluate weed control using different grain production systems. The treatments were: I. "Harvest-fallow" System-soybean/fallow/corn/fallow/rice/ fallow/soybean; II. "Harvest-green manure" System-soybean/millet/maize/pigeon pea/rice/ Crotalaria/soybean; III. "Harvest-out of season" System-soy/white oats/corn/dry bean/rice/castor oil/soybean; and IV "Harvest-fodder" System-brachiaria + soy/corn + brachiaria/brachiaria + rice/ soybeans. A weed survey was carried out in November 2009, after three growing seasons. A $0.3 \times 0.3 \mathrm{~m}$ frame was randomly launched four times within each plot. The plants were identified, and the total number of weeds, dry weight, and control percentage of the species were determined according to the production system. The phytosociological analysis of the weed community was also conducted. The systems Harvest-green manure; Harvest-out of season and Harvest-fodder presented a good weed control when compared to the Harvest-fallow system. Therefore, the presence of some type of soil cover is important to maintain favorable soil characteristics and good weed control.
\end{abstract}

Keywords: crop rotation, weed, green manure, out of season, crop-livestock integration.

1 Recebido para publicação em 10.2.2011 e aprovado em 15.6.2011.

Parte da Dissertação de Mestrado do primeiro autor.

2 Doutorando em Agronomia - Agricultura, Dep. de Produção Vegetal, Faculdade de Ciências Agronômicas, Universidade Estadual Paulista -FCA/UNESP, Campus de Botucatu, Caixa Postal 237, 18603-970 Botucatu-SP, Bolsista FAPESP,<gsacastro@hotmail.com>;

${ }^{3}$ Professor Titular, Dep. de Produção Vegetal, FCA/UNESP, Botucatu, Bolsista do CNPq, <crusciol@fca.unesp.br>; ${ }^{4}$ Engenheiro Agrônomo, Dr., TechField, FCA/UNESP, Botucatu e Eduvale/Avaré, <eduardo.negrisoli@gmail.com>; ${ }^{5}$ Doutorando em Agronomia - Agricultura, FCA/UNESP, Botucatu, <lperim@fca.unesp.br>.

Planta Daninha, Viçosa-MG, v. 29, p. 1001-1010, 2011. Número Especial 


\section{INTRODUÇÃO}

Entre os fatores bióticos capazes de proporcionar redução no rendimento das culturas encontram-se as plantas daninhas, as quais podem afetar a produção agrícola e econômica, devido, principalmente, às interferências negativas impostas por sua presença, como a competição por água, nutrientes, luz e efeitos alelopáticos. Além disso, as plantas daninhas podem ser hospedeiras de pragas, agentes causadores de doenças e nematoides, dificultar a operação de colheita ou mesmo depreciar a qualidade final do produto colhido, causando, assim, aumento significativo nos custos de produção (Christoffoleti \& Passini, 1999).

A prática de pousio para o controle de plantas daninhas tem uma longa história de sucesso, especialmente quando se imperava o cultivo convencional. No entanto, trabalhos sugerem que culturas de entressafra podem ser supressoras das plantas daninhas (Derksen et al., 1994), assim como sistemas alternados, como o safra-safrinha e safra-adubo verde.

Atualmente, o controle de plantas daninhas se dá, predominantemente, pelo método químico, com a aplicação de herbicidas. Contudo, essa medida, utilizada isoladamente, não é suficiente para eliminar toda a interferência das plantas daninhas sobre as culturas, exigindo medidas integradas de controle. A execução de um programa de manejo integrado de plantas daninhas prevê o pleno atendimento a quatro etapas de planejamento: o diagnóstico do problema, a escolha do método a ser utilizado, a seleção e, por último, a avaliação do programa de controle (Christoffoleti \& Passini, 1999).

A não movimentação do solo, a cobertura vegetal permanente e a rotação de culturas, preconizadas no Sistema de Semeadura Direta (SSD), podem resultar em menor germinação das sementes no solo. De acordo com a espécie e a quantidade dessa cobertura, as substâncias alelopáticas e o efeito do sombreamento determinam variações na intensidade e frequência de emergência das espécies daninhas (Teasdale et al., 1991).

A capacidade de supressão de plantas daninhas por culturas de cobertura é conhecida e explorada, embora seja pouco pesquisada a importância relativa dos efeitos de natureza física, química e biológica sobre esse fenômeno (Mateus at al., 2004).

$\mathrm{O}$ efeito físico da cobertura morta pode interferir na germinação e na taxa de sobrevivência das plântulas de algumas espécies de plantas daninhas. Nos efeitos sobre o processo germinativo, pode ocorrer a redução da germinação de sementes fotoblásticas positivas, as quais requerem determinado comprimento de onda para germinar, e a redução da germinação de sementes que necessitam de grande amplitude térmica para iniciar o processo germinativo (Guimarães et al., 2002).

Outro efeito promovido pelas plantas de coberturas é a ação alelopática, sendo o efeito mais ou menos específico. Segundo Lorenzi (1984), a mucuna-preta (Mucuna aterrima) exerce forte e persistente ação inibitória sobre a tiririca (Cyperus rotundus) e o picão-preto (Bidens pilosa). Aos 120 dias após a emergência da mucuna-preta, Medeiros (1989) não verificou presença de outras espécies, atribuindo isso a efeitos alelopáticos.

Podem-se citar ainda os efeitos relacionados à competição por água, luz, oxigênio e nutrientes. Trabalhos realizados nas Filipinas, citados por Altieri et al. (1978), apontaram excelente controle de plantas espontâneas pela associação de milho (Zea mays) com feijãomungo (Phaseolus mungo). O consórcio entre girassol (Helianthus annuus) e feijoeiro (Phaseolus vulgaris) reduziu em 38 e $22 \%$ a massa seca de plantas espontâneas, em relação, respectivamente, ao cultivo solteiro de feijoeiro e girassol (Machado, 1983).

A fitomassa de Arachis pintoi, Crotalaria juncea e Cajanus cajan incorporada ou na superficie reduziu significantemente as populações das plantas daninhas Brachiaria decumbens, Panicum maximum e Bidens pilosa (Favero et al., 2001). As espécies C. spectabilis, S. bicolor, C. ochroleuca, $M$. aterrima e $M$. pruriens reduziram significativamente a infestação e o peso da matéria seca das plantas daninhas $D$. horizontalis, H. lophanta e A. spinosus, enquanto a espécie $P$. glaucum foi menos eficiente nesse efeito (Erasmo et al., 2004).

O cultivo consorciado de grãos com forrageiras, sobretudo do gênero Brachiaria, 
pode promover a supressão da emergência das plantas daninhas em virtude da rapidez de produção de biomassa dessas espécies no período de estabelecimento, ou seja, após a colheita da cultura produtora de grãos (Borghi et al., 2008).

$\mathrm{Na}$ região do cerrado brasileiro, as áreas utilizadas para produção de grãos permanecem em pousio aproximadamente oito meses, quando se adota apenas uma safra por ano agrícola, em virtude das condições climáticas, devido principalmente à deficiência hídrica (Aidar et al., 2003). Em regiões com essa característica climática, não sendo possível o cultivo de culturas anuais de outono e/ou de inverno, pode-se optar pela produção de culturas forrageiras na entressafra em sucessão à cultura anual de verão ou de safrinha, seja semeada em consórcio ou solteira.

Segundo Voll et al. (1995), levantamentos de espécies daninhas, por amostragens da flora emergente, devem permitir a identificação e a quantificação das plantas infestantes, bem como a determinação da sua evolução. Esses conhecimentos podem ser usados na predição da necessidade de controle, adequando diferentes manejos de solo, da cultura e as sucessões a serem utilizadas, buscando a racionalização do uso de herbicidas, com base em considerações de custo/benefício do sistema de produção agrícola.

Tendo em vista o exposto, hipoteticamente, é possivel inferir que diferentes sistemas de produção de grãos e espécies utilizadas em um sistema de rotação de culturas podem influenciar a dinâmica de ocorrência e, consequentemente, do controle de plantas daninhas, podendo acarretar redução do uso de herbicidas.

Assim, objetivou-se neste trabalho avaliar a incidência e o controle de plantas daninhas em função de sistemas de produção de grãos em semeadura direta, em região de inverno seco.

\section{MATERIAL E MÉTODOS}

O experimento foi conduzido na Fazenda Experimental Lageado, pertencente à Faculdade de Ciências Agronômicas - UNESP, localizada no município de Botucatu (SP). O solo do local é do tipo Latossolo Vermelho distroférrico típico argiloso, profundo, ácido (Embrapa, 2006).

O delineamento experimental foi em blocos casualizados, com oito repetições. As parcelas foram constituidas por quatro sistemas de produção (I. Sistema "safra-pousio": sojapousio/milho-pousio/arroz-pousio; II. Sistema "safra-adubo verde": soja-milheto/milhoguandu/arroz-crotalária; III. Sistema "safrasafrinha": soja - aveia-branca/milho-feijão/ arroz-mamona; e IV. Sistema "safra-forrageira”: soja-braquiária/milho-braquiária/ arroz-braquiária).

As parcelas tiveram as dimensões de $5,4 \mathrm{~m}$ de largura e $30 \mathrm{~m}$ de comprimento, totalizando $162 \mathrm{~m}^{2}$. A área útil foi constituída da parte central da parcela, desprezando-se 0,5 de cada lado das extremidades. Antes da semeadura de cada cultura, foi realizada a dessecação das plantas presentes na área, com a utilização do herbicida glyphosate na dose de 1.800 gramas em equivalente ácido (e.a.), correspondendo a 2,5 kg de p.c. ha ${ }^{-1}$, empregando volume de aplicação de $200 \mathrm{~L} \mathrm{ha}^{-1}$. A operação foi realizada com pulverizador tratorizado de barras com $12 \mathrm{~m}$ de comprimento e ponta tipo leque XR 110.02, espaçadas de 0,50 m.

No primeiro ano agrícola, semeou-se (29 de novembro de 2006), sobre $4 \mathrm{t} \mathrm{ha}^{-1}$ de milheto, o cultivar de soja Embrapa 48, obedecendo a um espaçamento de $0,45 \mathrm{~m}$ e 22 plantas por metro. A adubação e os tratos culturais seguiram as recomendações para a cultura, respeitando-se as características químicas do solo e o nível de dano econômico das pragas e doenças para a cultura. Para o controle de plantas daninhas, foi feita uma aplicação com o Bentazone $\left(600 \mathrm{~mL} \mathrm{ha}^{-1}\right.$ do i.a.). O florescimento pleno da soja ocorreu 45 dias após sua emergência, e a colheita se deu no dia 3 de abril de 2007.

$\mathrm{Na}$ entressafra, a área experimental foi seccionada em quatro faixas, sendo três delas ocupadas por culturas e uma mantida em pousio. As culturas de entressafra (milheto, aveia-branca e braquiária) foram semeadas no dia 10 de abril de 2007, também em espaçamento de $0,45 \mathrm{~m}$. Para o milheto (cultivar BRS 1501) utilizaram-se $25 \mathrm{~kg}$ de sementes por hectare, objetivando população de $300 \mathrm{mil}$ 
plantas por hectare. Aos $50 \mathrm{DAE}$, quando ocorreu o florescimento pleno, foi realizado corte nas plantas a $15 \mathrm{~cm}$ do solo, para estimular a rebrota. Decorridos 35 dias dessa operação, foi realizado mais um corte, desta vez rente ao solo, quando as plantas atingiram novamente o estádio de florescimento. Para a aveia-branca, cultivar IAC 7, foram semeadas 130 sementes viáveis por metro quadrado. A cultura também floresceu 50 dias após a semeadura, sendo a colheita realizada no dia 30 de julho de 2007. Por fim, como forrageira, utilizou-se Brachiaria ruziziensis, na densidade de semeadura de $10 \mathrm{~kg} \mathrm{ha}^{-1}$ para o valor cultural de $25 \%$, com o objetivo de semear $2,5 \mathrm{~kg}$ de sementes puras viáveis por hectare. A braquiária permaneceu vegetando até novembro de 2007, uma semana antes da instalação da cultura de verão. As culturas de entressafra não receberam qualquer tipo de adubação ou outros tratos culturais.

No segundo ano agrícola, semeou-se (2/12/2007), em todo o experimento, o híbrido de milho 2B570 no espaçamento de 0,45 m entrelinhas e sementes necessárias para obter três plantas por metro. A adubação e os tratos culturais seguiram as recomendações para a cultura. Para controle de plantas daninhas, foi aplicado (dezembro de 2007) o herbicida pré-emergente atrazine (2.500 $\mathrm{g} \mathrm{ha}^{-1}$ do i.a.). O florescimento pleno do milho ocorreu 64 dias após sua emergência, e a colheita foi realizada no dia $11^{\circ}$ de abril de 2007.

Nessa entressafra, assim como na anterior, a área experimental foi seccionada em quatro faixas, sendo três delas ocupadas por culturas e uma mantida em pousio. As culturas de entressafra foram semeadas no dia 5 de abril de 2008, seguindo o espaçamento de $0,45 \mathrm{~m}$. Para a cultura do feijão, utilizou-se o cultivar Pérola, semeando-se 18 sementes por metro. O florescimento pleno do feijoeiro ocorreu 47 dias após sua semeadura, e a colheita, no dia 5 de julho de 2008. Quanto à cultura do guandu, semearam-se 20 sementes por metro do cultivar IAPAR 43. O florescimento pleno ocorreu no dia $1^{\circ}$ de julho de 2008. Nessa ocasião, procedeu-se à ceifa mecânica das plantas para estimular a rebrota, o que não ocorreu. A cultura da braquiária foi implantada na mesma densidade e espaçamento utilizados no primeiro ano, permanecendo em livre crescimento até outubro de 2008, uma semana antes da semeadura da cultura de verão. As culturas de entressafra não receberam qualquer tipo de adubação ou outros tratos culturais.

No terceiro ano agrícola, semeou-se (29/10/2008) o cultivar de arroz de terras altas IAC 202 no espaçamento de $0,45 \mathrm{~m}$ e 200 plantas por $\mathrm{m}^{2}$. A adubação e os tratos culturais seguiram as recomendações para a cultura. Para o controle de plantas daninhas, foi aplicado (dezembro de 2007) o herbicida tiobencarbe + propanil $\left(2.400\right.$ e $1.200 \mathrm{~kg} \mathrm{ha}^{-1}$ do i.a., respectivamente). O florescimento pleno se deu em 71 dias após a emergência, e a colheita ocorreu no dia 3 de abril de 2009.

As culturas de entressafra foram semeadas no dia 10 de abril de 2009, seguindo o espaçamento de $0,45 \mathrm{~m}$. Para a cultura da mamona (IAC 2028), foram semeadas três sementes viáveis por metro. O florescimento pleno da mamona ocorreu 80 dias após sua semeadura, e a colheita, no dia 30 de setembro de 2009. Para a cultura da crotalária, cultivar IAC-KR1, foram utilizados $25 \mathrm{~kg}$ de sementes por hectare. O florescimento pleno ocorreu 70 dias após sua semeadura, quando se procedeu à ceifa mecânica das plantas para estimular a rebrota, o que praticamente não ocorreu. A cultura da braquiária foi implantada na mesma densidade e espaçamento utilizados nos primeiros anos, permanecendo em livre crescimento até outubro de 2009. As culturas de entressafra não receberam qualquer tipo de adubação ou outros tratos culturais.

As coletas e avaliações foram realizadas antes da dessecação da área para a semeadura da safra de verão 2009/2010, em novembro de 2009. Para o levantamento das espécies infestantes, foi utilizado como unidade amostral um quadro $(0,3 \times 0,3 \mathrm{~m})$, lançando-se quatro quadros aleatoriamente dentro de cada parcela de estudo, por meio de um caminhamento em zigue-zague. Em cada quadro amostrado, as plantas foram identificadas, bem como feita a determinação do número total presente das espécies invasoras, da matéria seca e da porcentagem de controle de plantas daninhas. O material coletado foi seco em estufa de circulação forçada de ar a $60^{\circ} \mathrm{C}$, 
sendo pesado em seguida, e os dados, transformados em $\mathrm{kg} \mathrm{ha}^{-1}$. Quanto à porcentagem de controle, levou-se em consideração a redução do número de plantas daninhas por hectare, comparativamente ao sistema safrapousio, que recebeu o valor de $0 \%$ de controle.

Realizou-se também a caracterização fitossociológica e a avaliação da comunidade infestante. Em cada quadro amostrado, as plantas daninhas foram identificadas segundo família, gênero e espécie; determinou-se também o número de cada espécie presente. Em função dos dados obtidos, foram estimadas as variáveis: frequência $(\mathrm{Fr})$, densidade $(\mathrm{De})$ e abundância $(\mathrm{Ab})$. Destas, foram obtidas as variáveis: frequência relativa (Frr), densidade relativa (Der) e abundância relativa (Abr), além do indice de valor de importância (IVI), seguindo a metodologia empregada por Brandão et al. (1998) e Brighenti et al. (2003), que utilizaram as seguintes fórmulas:

$\mathrm{Fr}=$ № de parcelas que contêm a espécie / № total de parcelas estudadas (1)

$\mathrm{De}=$ № total de indivíduos por espécie / Área total amostrada (2)

$\mathrm{Ab}=$ № total de indivíduos por espécie / № total de parcelas que contêm a espécie (3)

Frr $=$ Fr de cada espécie $\mathrm{x} 100 /$ Fr total de todas as espécies (4)

Der $=$ De da espécie $\times 100 /$ De total de todas as espécies (5)

$\mathrm{Abr}=\mathrm{Ab}$ da espécie $\times 100 / \mathrm{Ab}$ total de todas as espécies (6)

$\mathrm{IVI}=\mathrm{Frr}+\mathrm{Der}+\mathrm{Abr}(7)$

Os dados obtidos, com exceção da caracterização fitossociológica, foram submetidos à análise da variância pelo teste $\mathrm{F}$, e as médias dos tratamentos, comparadas pelo teste DMS a 5\% de probabilidade.

\section{RESULTADOS E DISCUSSÃO}

Na Tabela 1 estão descritas as espécies de plantas daninhas identificadas nos quatro sistemas de produção, antes da semeadura da soja, em novembro de 2009, com sua respectiva família, nome científico, nome vulgar e código internacional, de acordo com Kissmann \& Groth (2000). Foram identificadas nove espécies, distribuídas em sete famílias, destacando-se as familias Amaranthaceae e Asteraceae, com duas espécies. As famílias Commelinaceae, Convolvulaceae, Euphorbiaceae, Lamiaceae e Poaceae apresentaram apenas uma espécie cada.

Na Tabela 2 encontram-se os valores médios de produção de matéria seca de cada cultura dentro dos sistemas de produção de grãos, ao longo de três anos agrícolas. Observase diferença entre os sistemas devido às culturas de entressafra, visto que as culturas de verão (soja, milho e arroz) não diferiram dentro de cada sistema. A maior produção de palha se deu no sistema safra-forrageira (cultivado com braquiária nas entressafras), seguido pelo sistema safra-adubo verde (onde se cultivou milheto, guandu e crotalária na entressafra). O sistema safra-safrinha (cuja entressafra constou de aveia-branca, feijão e mamona) não diferiu do sistema safra-pousio (que não foi cultivado na entressafra) quanto à produção total de palha, mesmo produzindo mais palha durante as três entressafras avaliadas, provavelmente pela baixa produção de palha do feijão. A produção de palha pela forrageira só foi menor que a produção de

Tabela 1 - Identificação das plantas daninhas avaliadas

\begin{tabular}{|c|c|c|c|}
\hline Família & Espécie & Nome vulgar & Código \\
\hline Amaranthaceae & Alternanthera tenella & Apaga-fogo & ALRTE \\
\hline Amaranthaceae & Amaranthus retroflexus & Caruru & AMARE \\
\hline Asteraceae & Bidens pilosa & Picão-preto & BIDPI \\
\hline Asteraceae & Emilia sonchifolia & Falsa-serralha & EMISO \\
\hline Commelinaceae & Commelina benghalensis & Trapoeraba & COMBE \\
\hline Convolvulaceae & Ipomoea hederifolia & Corda-de-viola & IPOHF \\
\hline Euphorbiaceae & Ricinus communis & Mamona & RIICO \\
\hline Lamiaceae & Leonotis nepitifolia & Cordão-de-frade & LEONE \\
\hline Poaceae & Eleusine indica & Capim pé-de-galinha & ELEIN \\
\hline
\end{tabular}


Tabela 2 - Produção de matéria seca das culturas de safra e entressafra nos diferentes sistemas de produção de grãos

\begin{tabular}{|l|c|c|c|c|c|c|c|c|}
\hline \multirow{2}{*}{ Sistema de produção } & Soja & Entressafra & Milho & Entressafra & Arroz & Entressafra & Total \\
\cline { 2 - 8 } & \multicolumn{7}{|c|}{$\left(\mathrm{kg} \mathrm{ha}^{-1}\right)$} \\
\hline Safra-pousio & $3181 \mathrm{a}$ & $3025 \mathrm{~d}$ & $11.501 \mathrm{a}$ & $1204 \mathrm{c}$ & $5196 \mathrm{a}$ & $2840 \mathrm{c}$ & $2.6947 \mathrm{c}$ \\
\hline Safra-adubo verde & $3336 \mathrm{a}$ & $6546 \mathrm{a}$ & $11.529 \mathrm{a}$ & $1805 \mathrm{~b}$ & $5748 \mathrm{a}$ & $4060 \mathrm{~b}$ & $3.3024 \mathrm{~b}$ \\
\hline Safra-safrinha & $3051 \mathrm{a}$ & $3603 \mathrm{c}$ & $11.309 \mathrm{a}$ & $1014 \mathrm{c}$ & $4664 \mathrm{a}$ & $3567 \mathrm{~b}$ & $2.7208 \mathrm{c}$ \\
\hline Safra-forrageira & $3025 \mathrm{a}$ & $4999 \mathrm{~b}$ & $11.549 \mathrm{a}$ & $6499 \mathrm{a}$ & $5644 \mathrm{a}$ & $6481 \mathrm{a}$ & $3.8177 \mathrm{a}$ \\
\hline \multicolumn{1}{|c|}{ F $_{\text {calc. }}$} & $0,75 \mathrm{~ns}$ & $8,67 *$ & $0,24 \mathrm{~ns}$ & $12,82^{* *}$ & $0,41 \mathrm{~ns}$ & $15,55^{*}$ & $5,99^{*}$ \\
\hline CV(\%) & 10,54 & 12,25 & 8,49 & 15,74 & 10,92 & 11,55 & 11,64 \\
\hline DMS & 402 & 511 & 794 & 290 & 1656 & 688 & 3259 \\
\hline
\end{tabular}

**, * e ns: significativo a $1 \%$, a $5 \%$ e não significativo, respectivamente, pelo teste $\mathrm{F}$. Médias seguidas de letras distintas na coluna diferem estatisticamente pelo teste de Tukey $(p<0,05)$.

milheto, no primeiro ano do sistema safraadubo verde. Nos demais, $B$. ruziziensis foi o que mais aportou palhada ao sistema. De acordo com Severino et al. (2006), a alta produtividade das forrageiras, mesmo quando em competição com plantas daninhas, se deve ao livre crescimento da cultura durante toda a entressafra, o que permite maior acúmulo de biomassa pela forrageira, diminuindo assim os recursos necessários para o desenvolvimento das plantas daninhas.

Além da produção de matéria seca, dois fatores influenciaram a supressão de plantas daninhas: o ciclo da cultura e a relação $\mathrm{C} / \mathrm{N}$ dos materiais vegetais - este último interfere diretamente na persistência da cobertura morta. O ciclo médio das culturas de entressafra, considerando da semeadura até o manejo ou colheita, foi de 80 dias no sistema safra-adubo verde e de 90 dias no sistema safra-safrinha, apesar do longo ciclo da mamona. Nesse critério, a forrageira levou vantagem, visto que ela permaneceu vegetando até sua dessecação, em geral 15 dias antes da semeadura da cultura de verão, permanecendo na área por cerca de sete meses. As gramíneas, de modo geral, possuem relação $\mathrm{C} / \mathrm{N}$ superior à das leguminosas. Dessa forma, os restos vegetais da braquiária tendem a manter uma boa cobertura vegetal por maior tempo, principalmente quando comparado aos restos vegetais dos sistemas safra-safrinha e safraadubo verde, que foram cultivados na entressafra com duas espécies leguminosas e apenas uma gramínea.

As médias da população e produção de matéria seca das plantas daninhas em cada sistema de produção e seu respectivo controle em comparação com o sistema safra-pousio estão inseridos na Tabela 3. A presença de Brachiaria ruziziensis no sistema safra-forrageira proporcionou a maior redução de matéria seca das plantas daninhas e na quantidade de plantas daninhas na área, proporcionando ótimo controle, em relação ao pousio $(97,7 \%)$. Os demais sistemas de produção também foram eficientes em reduzir o desenvolvimento e a germinação de plantas daninhas na área; os benefícios da safrinha (sistema safrasafrinha) atingiram $86,6 \%$ de controle, sendo superiores aos obtidos pelo sistema safra-adubo verde $(54,9 \%$ de controle), provavelmente pelo maior período vegetativo das culturas utilizadas na safrinha.

A redução na população de plantas daninhas na cultura do milho proporcionada por plantas de cobertura também foi relatada por

Tabela 3 - População (no plantas por área), matéria seca $\left(\mathrm{kg} \mathrm{ha}^{-1}\right)$ e controle de plantas daninhas (\%) em função do sistema de produção de grãos

\begin{tabular}{|c|c|c|c|}
\hline \multirow{2}{*}{ Sistema de produção } & População & Matéria Seca & Controle \\
\hline & $\left(\mathrm{n}^{\mathrm{o}}\right.$ plantas $\left.\mathrm{m}^{-2}\right)$ & $\left(\mathrm{kg} \mathrm{ha}^{-1}\right)$ & $(\%)$ \\
\hline I. Safra-pousio & $8,25 \mathrm{c}$ & $4.168 \mathrm{~d}$ & $0,0 \mathrm{~d}$ \\
\hline II. Safra-adubo verde & $3,73 \mathrm{~b}$ & $2.490 \mathrm{c}$ & $54,9 \mathrm{c}$ \\
\hline III. Safra-safrinha & $1,02 \mathrm{a}$ & $1.663 \mathrm{~b}$ & $87,6 \mathrm{~b}$ \\
\hline IV. Safra-forrageira & $0,19 \mathrm{a}$ & $308 \mathrm{a}$ & $97,7 \mathrm{a}$ \\
\hline $\mathrm{CV}(\%)$ & 23,87 & 13,52 & 10,31 \\
\hline $\mathrm{F}_{\text {calc }}$ & $92,6^{* *}$ & $122 * *$ & $243 * *$ \\
\hline DMS & 1,3 & 466 & 7,95 \\
\hline
\end{tabular}

** significativo a $1 \%$ pelo teste $\mathrm{F}$. Médias seguidas de letras distintas na coluna diferem estatisticamente pelo teste de Tukey $(p<0,05)$. 
Fernandez et al. (2008) e Aladesanwa \& Adigun (2008). Segundo Silva et al. (2009), que estudaram o efeito de adubos verdes na supressão de plantas daninhas, as espécies Pannisetum glaucum e Crotalarea juncea proporcionam eficiente controle sobre espécies infestantes. Da mesma forma, foi constatado por Severino et al. (2006) que a produção de B. ruziziensis na entressafra promove redução da emergência e supressão das plantas daninhas em virtude da rapidez de produção de biomassa dessa espécie no período de estabelecimento (após a colheita da cultura produtora de grãos), com efeito benéfico para o sistema de produção.

Este estudo evidencia que a presença e o desenvolvimento de plantas daninhas sofrem influência dos sistemas de produção utilizados. Entretanto, independentemente do sistema, a utilização de uma cultura durante a entressafra resultou na redução de todas as variáveis avaliadas. Nas áreas em pousio, provavelmente o livre crescimento das plantas daninhas durante a entressafra tenha propiciado a manutenção e o crescimento do banco de sementes, acarretando sua reinfestação no ano agrícola seguinte, elevando o número de espécies e a agressividade da infestação durante a safra de verão. Erasmo et al. (2004), comparando três manejos culturais distintos, verificaram que a produção de arroz sem rotação de cultura por mais de cinco anos proporcionou maior número de plantas daninhas, principalmente das famílias Poaceae e Compositae. Silva et al. (2009), estudando a produção de palha e a supressão de plantas daninhas por plantas de cobertura em sistema plantio direto, concluíram que os adubos verdes Pannicetum glaucum e Crotalarea juncea, isolados e consorciados entre si, reduziram a germinação e o acúmulo de matéria seca de plantas daninhas.

Neste estudo, verificou-se com a análise fitossociológica da comunidade de plantas daninhas, identificadas antes da instalação da safra 2009/10 (Tabela 4), que houve predomínio das espécies dicotiledôneas em relação às monocotiledôneas, em todos os tratamentos. Constatação semelhante foi descrita por Mateus et al. (2004), os quais observaram que houve predomínio de folhas largas em relação às gramíneas - fato atribuído ao banco de sementes existente na área experimental e ao manejo dos herbicidas de anos anteriores.

No sistema safra-pousio, Bidens pilosa foi a espécie que apresentou os maiores valores de frequência relativa $(\mathrm{Fr})$, densidade relativa (Dr), abundância relativa (Ar) e importância relativa (Ir) - 7, 29 e 48 e 84\%, respectivamente - seguida por Emilia fosbergii e Chloris barbata $(21,26,14$ e 64 ; e $29,23,9$ e $61 \%$, respectivamente, de Fr, Dr, Ar e Ir). No sistema safraadubo verde, houve redução do número total de indivíduos e alteração na ordem das plantas daninhas mais relevantes; Chloris barbata foi a espécie que obteve os maiores valores de Fr, Dr, Ar e Ir: 36, 58, 25 e 119\%, respectivamente. Já no sistema safra-safrinha, observou-se drástica redução no número total de indivíduos e também na variedade de espécies infestantes, mais uma vez com destaque para a gramínea Chloris barbata. Por fim, o sistema safra-forrageira foi o que proporcionou o menor número de espécies infestantes e número total de indivíduos, evidenciando o controle proporcionado por B. ruziziensis. Leonotis nepitifolia e Emilia fosbergii apresentaram Fr de 50\%, Dr de 50\%, Ar de $50 \%$ e Ir de $150 \%$. Nota-se que este último sistema foi o único capaz de eliminar a presença de Chloris barbata na área, provavelmente pela forte competição por luz e nutrientes entre as duas gramineas.

Esse resultado é decorrente do efeito da produção de matéria seca de $B$. ruziziensis nos anos anteriores, que se beneficiou do maior período de vegetação e consequente maior interceptação da radiação incidente, proporcionando maior acúmulo de biomassa durante as três safras agrícolas. Dessa forma, esse maior aporte de palhada sobre a superficie pode ter atuado como barreira física à emergência das plantas daninhas (Theisen et al., 2000). Entre exemplos típicos, pode-se mencionar o cultivo mínimo em áreas de reflorestamento com manutenção da serrapilheira sobre o solo, o sistema de produção de cana-crua e, com maior adoção, o plantio direto de culturas anuais (Velini \& Negrisoli, 2000). Do mesmo modo, de acordo com Severino et al. (2006), o cultivo de forrageiras na entressafra tem sido uma das práticas eficientes na supressão de plantas daninhas, por proporcionar diferentes modelos de competição e alelopatia, reduzindo 
Tabela 4 - Análise fitossociológica da comunidade de plantas daninhas identificadas nos diferentes sistemas de produção, no ano de 2009

\begin{tabular}{|c|c|c|c|c|c|c|c|}
\hline \multirow{2}{*}{$\begin{array}{l}\text { Sistema de } \\
\text { produção }\end{array}$} & \multirow{2}{*}{ Espécie } & \multirow{2}{*}{$\begin{array}{l}\text { Quadros } \\
\text { ocupados }\end{array}$} & \multirow{2}{*}{$\begin{array}{c}\mathrm{N}^{\mathrm{o}} \mathrm{de} \\
\text { Indivíduos }\end{array}$} & $\mathrm{Fr}$ & $\mathrm{Dr}$ & $\mathrm{Ar}$ & $\mathrm{Ir}$ \\
\hline & & & & \multicolumn{4}{|c|}{$(\%)$} \\
\hline \multirow{7}{*}{ Safra-pousio } & Eleusine indica & 32 & 280 & 29 & 23 & 9 & 61 \\
\hline & Emilia sonchifolia & 24 & 320 & 21 & 26 & 14 & 62 \\
\hline & Bidens pilosa & 8 & 352 & 7 & 29 & 48 & 84 \\
\hline & Alternanthera tenella & 8 & 88 & 7 & 7 & 12 & 26 \\
\hline & Leonotis nepitifolia & 24 & 72 & 21 & 6 & 3 & 31 \\
\hline & Amaranthus retroflexus & 8 & 56 & 7 & 5 & 8 & 19 \\
\hline & Ipomoea hederifolia & 8 & 40 & 7 & 3 & 5 & 16 \\
\hline Total & - & 112 & 1208 & 100 & 100 & 100 & 300 \\
\hline \multirow{8}{*}{ Safra-adubo verde } & Eleusine indica & 32 & 336 & 36 & 58 & 25 & 119 \\
\hline & Emilia sonchifolia & 8 & 48 & 9 & 8 & 14 & 32 \\
\hline & Commelina benghalensis & 8 & 40 & 9 & 7 & 12 & 28 \\
\hline & Leonotis nepitifolia & 8 & 48 & 9 & 8 & 14 & 32 \\
\hline & Alternanthera tenella & 8 & 48 & 9 & 8 & 14 & 32 \\
\hline & Amaranthus retroflexus & 8 & 24 & 9 & 4 & 7 & 20 \\
\hline & Ricinus communis & 8 & 24 & 9 & 4 & 7 & 20 \\
\hline & Ipomoea hederifolia & 8 & 16 & 9 & 3 & 5 & 17 \\
\hline Total & - & 88 & 584 & 100 & 100 & 100 & 300 \\
\hline \multirow{3}{*}{ Safra-safrinha } & Eleusine indica & 32 & 160 & 67 & 63 & 29 & 159 \\
\hline & Emilia sonchifolia & 8 & 40 & 17 & 16 & 29 & 62 \\
\hline & Leonotis nepitifolia & 8 & 56 & 17 & 22 & 41 & 80 \\
\hline Total & - & 48 & 256 & 100 & 100 & 100 & 300 \\
\hline \multirow{2}{*}{ Safra-forrageira } & Leonotis nepitifolia & 8 & 24 & 50 & 50 & 50 & 150 \\
\hline & Emilia sonchifolia & 8 & 24 & 50 & 50 & 50 & 150 \\
\hline Total & - & 16 & 48 & 100 & 100 & 100 & 300 \\
\hline
\end{tabular}

assim o banco de sementes e a pressão de seleção sobre plantas daninhas específicas. O efeito alelopático pode atuar diretamente (quando a substância interfere no metabolismo vegetal) e/ou indiretamente (quando altera, primeiramente, algumas propriedades do solo) de uma planta sobre a outra, tanto em comunidades naturais como em cultivadas (Rice, 1984; Ferreira \& Aquila, 2000). Os efeitos alelopáticos encontrados em algumas espécies utilizadas como adubos verdes - prática intrínseca do plantio direto - auxiliam no controle da infestação de plantas daninhas, devido aos efeitos físico-químicos proporcionados pela palhada que se acumula na superficie do solo (Erasmo et al., 2004; Duarte Júnior et al., 2009). Nesse sentido, Mateus et al. (2004) observaram que o incremento na produção de palhada propiciou controle de até $100 \%$ na emergência de plantas daninhas, fato este atribuído aos efeitos alelopáticos promovidos pelas plantas de cobertura.

Já a espécie Bidens pilosa, de maior Ir no sistema safra-pousio, foi controlada nos três sistemas de rotação durante a entressafra. Esse resultado pode indicar que essa espécie não é tão competitiva quanto as demais, sendo suplantada pelas culturas comerciais, desde que o sistema de produção de grãos tenha, praticamente, cultivos ininterruptos.

Esses resultados permitem evidenciar o aspecto conservacionista proporcionado pelo sistema plantio direto, bem como o potencial desse sistema na redução da densidade da população das plantas daninhas, diminuindo gradualmente o banco de sementes ao longo dos anos; com isso, pode reduzir ou eliminar, 
em determinados anos agrícolas, a necessidade de herbicidas. Pereira \& Velini (2003) relatam que o sistema plantio direto ou preparo superficial do solo resulta na concentração de sementes próximo à superfície, o que tende a acelerar o decréscimo de sementes recémderrubadas ao solo, pela indução de germinação ou pela perda de viabilidade. Esses autores ressaltam ainda que o sistema plantio direto bem conduzido pode proporcionar maior eficiência no controle cultural das plantas daninhas, reduzindo o número total de indivíduos e a diversidade da comunidade infestante.

Portanto, destaca-se a importância da rotação de culturas dentro dos sistemas de produção de grãos, uma vez que, além de manter as características do solo favoráveis, assegura um bom controle de plantas daninhas. Esses resultados evidenciam a importância e a necessidade de se estudar o efeito dos sistemas de produção agrícola na dinâmica de estabelecimento e desenvolvimento das plantas daninhas, pois fica evidente que o planejamento da rotação e/ou sucessão de culturas pode ser uma das práticas de extrema relevância na composição do manejo integrado de plantas daninhas.

Pode-se concluir que, em relação ao sistema safra-pousio, os sistemas safra-adubo verde, safra-safrinha e safra-forrageira reduzem a infestação, o desenvolvimento e a proliferação de plantas daninhas, auxiliando no controle destas. Entre os sistemas, destacase o safra-forrageira, que proporciona controle superior a $97 \%$, sendo uma alternativa viável para o manejo integrado de plantas daninhas.

\section{LITERATURA CITADA}

AIDAR, H.; RODRIGUES, J. A. S.; KLUTHCOUSKI, J. Uso da integração lavoura-pecuária para produção de forragem na entressafra. In: KLUTHCOUSKI, J.; STONE, L. F.; AIDAR, H. Integração lavoura-pecuária. Santo Antonio de Goiás: Embrapa Arroz e Feijão, 2003. p. 225-262.

ALADESANWA, R. D.; ADIGUN, A. W. Evaluation of sweet potato (Ipomoea batatas) live mulch at different spacings for weed suppression and yield response of maize (Zea mays L.) in southwestern Nigeria. Crop Protec., v. 27, n. 6, p. 968-975, 2008.

ALTIERI, M. A. et al. A review of insect prevalence in maize (Zea mays L.) and bean (Phaseolus vulgaris L.) polycultural systems. Field Crops Res., v. 1, p. 33-49, 1978.
BORGHI, E. et al. Influência da distribuição espacial do milho e da Brachiaria brizantha consorciados sobre a população de plantas daninhas em sistema de plantio direto na palha.

Planta Daninha, v. 26, n. 3, p. 559-568, 2008.

BRANDÃO, M.; BRANDÃO, H.; LACA-BUENDIA, J. P. A mata ciliar do rio Sapucaí, município de Santa Rita do Sapucaí-MG: fitossociologia. Daphne, v. 8, n. 4, p. 36-48, 1998.

BRIGHENTI, A. M. et al. Cadastramento fitossociológico de plantas daninhas na cultura do girassol no município de Chapadão do Céu, GO. B. Inf. SBCOD, v. 9, n. 1, p. 5-8, 2003.

CHRISTOFFOLETI, P. J.; PASSINI, T. Manejo integrado de plantas daninhas na cultura do feijão. In: FANCELLI, A. L.; DOURADO NETO, D. Feijão irrigado: estratégias básicas de manejo. Piracicaba: LPV/ESALQ/USP, 1999. p. 80-97.

DERKSEN, D. A., THOMAS, A. G., LAFORD, H. A. et al Impact of agronomic practices on weed communities: fallow withim tillage systems. Weed Sci., v. 42, n. 2, p. 184-194, 1994.

DUARTE JÚNIOR, J. B; COELHO, F. C.; FREITAS, S. P. Dinâmica de populações de plantas daninhas na cana-deaçúcar em sistema de plantio direto e convencional. Semina, v. 30, n. 3 , p. $595-612,2009$

EMPRESA BRASILEIRA DE PESQUISA AGROPECUÁRIA - EMBRAPA. Centro Nacional de Pesquisa de Solos. Sistema brasileiro de classificação de solos. 2.ed. Rio de Janeiro, 2006. 306 p.

ERASMO, E. A. L. et al. Potencial de espécies utilizadas como adubo verde no manejo integrado de plantas daninhas. Planta Daninha, v. 22, n. 3, p. 337-342, 2004.

FAVERO, C. et al. Modificações na população de plantas espontâneas na presença de adubos verdes. Pesq. Agropec. Bras., v. 36, n. 11, p. 1355-1362, 2001

FERNANDEZ, R. et al. A study of the effect of the interaction between site-specific conditions, residue cover and weed control on water storage during fallow. Agric. Water Manag., v. 95, n. 9, p. 1028-1040, 2008.

FERREIRA, A. G.; AQUILA, M. E. A. Alelopatia: uma área emergente da ecofisiologia. R. Bras. Fisiol. Vegetal, v. 12, n. 1, p. 175-204, 2000.

GUIMARÃES, S. C.; SOUZA, I. F.; PINHO, E. V. R. V. Emergência de Tridax procumbens em função da profundidade de semeadura, do conteúdo de argila no substrato e da incidência de luz na semente. Planta Daninha, v. 20, n. 3, p. 413-419, 2002. 
KISSMANN, K. G.; GROTH, D. Plantas infestantes e nocivas. 2.ed. São Paulo: BASF, 2000. Tomo III. 726 p.

LORENZI, H. Inibição alelopática de plantas daninhas. In FUNDAÇÃO CARGILL. Adubação verde no Brasil Campinas: Fundação Cargill, 1984. p. 183-198.

MACHADO, C. M. N. Eficiência da consorciação de culturas na utilização da terra e no controle de plantas daninhas. 1983. 120 f. Dissertação (Mestrado em Fitotecnia)

- Universidade Federal do Rio Grande do Sul, Porto Alegre, 1983.

MATEUS, G. P.; CRUSCIOL, C. A. C.; NEGRISOLI, E Palhada do sorgo de guiné gigante no estabelecimento de plantas daninhas em área de plantio direto. Pesq. Agropec. Bras., v. 39, n. 6, p. 539-542, 2004

MEDEIROS, A. R. M. Determinação de potencialidades alelopáticas em agroecossistemas. 1989. 92 f. Tese (Doutorado em Fitotecnia) - Escola Superior de Agricultura Luiz de Queiroz, Piracicaba, 1989

PEREIRA, F. A. R.; VELINI, E. D. Sistemas de cultivos no cerrado e dinâmica de populações de plantas daninhas.

Planta Daninha, v. 21, n. 3, p. 355-363, 2003.

RICE, E. L. Allelopathy. 2.ed. New York: Academic Press, 1984. $422 \mathrm{p}$.
SEVERINO, F. J.; CARVALHO, S. J. P.; CHRISTOFFOLETI, P. J. Interferências mútuas entre a cultura do milho, espécies forrageiras e plantas daninhas em um sistema de consórcio. III - implicações sobre as plantas daninhas. Planta Daninha, v. 24, n. 1, p. 53-60, 2006.

SILVA, A. C. et al. Produção de palha e supressão de plantas daninhas por plantas de cobertura, no plantio direto do tomateiro. Pesq. Agropec. Bras., v. 44, n. 1, p. 22-28, 2009 .

TEASDALE, J.R.; BESTE, C.E.; POTTS, W.E. Response of weeds to tillage and cover crop residue. Weed Sci., v. 39, n. 2, p. 195-199, 1991.

THEISEN, G.; VIDAL, R. A.; FLECK, N. G. Redução da infestação de Brachiaria plantaginea em soja pela cobertura do solo com palha de aveia preta. Pesq. Agropec. Bras., v. 35 , n. 4 , p. $753-756,2000$.

VELINI, E. D.; NEGRISOLI, E. Controle de plantas daninhas em cana-crua. In: CONGRESSO BRASILEIRO DA CIÊNCIA DAS PLANTAS DANINHAS, 22., Foz do Iguaçu, 2000. Palestras... Londrina: SBCPD, 2000. p. 148-164.

VOLL, E.; GAZZIERO, D. L. P.; KARAM, D. Dinâmica de populações de Brachiaria plantaginea (Link) Hitchc. sob manejos de solo e de herbicidas. I. Sobrevivência. Pesq. Agropec. Bras., v. 30, n. 12, p. 1387-1396, 1995. 